\title{
Numerical modelling of heat exchanger pile in pyroclastic soil
}

\author{
Gabriella Marone $^{l}$, Luca Di Girolamo ${ }^{I}$, Marianna Pirone $^{l}$, and Gianpiero Russo ${ }^{l}$ \\ ${ }^{1}$ Department of civil, architectural and environmental engineering, Polytechnique and Basic Sciences School, \\ University of Napoli Federico II, Via Claudio 21, 80125, Napoli, Italy.
}

\begin{abstract}
Energy piles are an innovative technology that couples the role of the structural foundation to the role of the heat exchanger to satisfy the energy needs of buildings and infrastructures. In the last decade insight into the mechanisms governing the thermo-mechanical response of single energy piles have been gained via full-scale in-situ tests, numerical analyses and model-scale experiments. The numerical approaches allow testing a large variety of configurations, geometries, materials, thermo-mechanical loadings and boundary conditions in a rather controlled but relatively easy and cost-effective manner. As a widespread habit it should be remarked that the temperature changes adopted in the piles have been only rarely justified based on realistic heating and cooling demands of live buildings. This numerical study investigates the effects of combination of mechanical and thermal loads on the mechanical behaviour of a single energy pile embedded in a typical pyroclastic soil deposit of Campania region, in Southern Italy. Thermal loads over one year have been determined by means of Design Builder software analysing a building in Napoli; the intermittent operation of the heat pump over daily time scale is properly modelled in the coupled thermo-hydro-mechanical axisymmetric FE analyses. A sensitivity analysis has been carried out to investigate the effects of the surface thermal boundary conditions.
\end{abstract}

\section{Introduction}

The use of energy piles is increasing around the world because they are an innovative technology that couples the role of the structural foundation to the role of the heat exchanger to satisfy the energy needs of buildings and infrastructures.

Polyethylene pipes are embedded into the concrete structures, and a heat-carrying fluid circulates through them and exchanges heat with the ground. The pipes are then connected to a heat pump system, which circulates the fluid in the heating-cooling plant of the building [1]. This system allows to extract heat from the ground during winter and to inject it into the ground during summer to satisfy buildings' energy demand. Several efforts have been devoted to the investigation of such structures via full-scale in-situ test $[2,3,4]$, numerical analyses $[5,6,7,8,9]$ and model-scale experiments $[10$, 11, 12]. Numerical approaches allow testing a large variety of configurations, geometries, materials, thermomechanical loadings and boundary conditions in a rather controlled but relatively easy and cost-effective manner. In this study, the mechanical behaviour of a single energy pile embedded in a typical pyroclastic soil deposit of Campania region (Southern Italy) has been investigated by thermo-mechanical axisymmetric FE analyses. It should be remarked that the temperature changes adopted along the piles have been only rarely defined considering heating and cooling demands of buildings. In this study, thermal loads over one year, typical for a building in Napoli, have been determined by means of Design Builder software. The intermittent operation of the heat pump over hourly and daily time scales is properly modelled. In addition, different surface thermal boundary conditions have been investigated: $i$. outdoor environmental temperatures; ii. indoor temperatures of a typical civil building (the superstructure).

\section{Building conditioning simulation}

Thermo-mechanical behaviour of energy piles is certainly influenced by the magnitude, numbers and duration of thermal cycles. Human activities carried out in the building, building urbanistic usage and geographic location influence thermal loadings determination. In this study a four-storey building, office intended use, with a rectangular shape in plan, $9.00 \mathrm{~m} \times 16.25 \mathrm{~m}$, located in the South of Italy (Napoli) has been modelled.

To design the plant and its components, geothermal heat exchangers as well as the size and type of Ground Source Heat Pump (GSHP) have been fixed. A calculation of the indoor peak thermal demand in summer and winter has been done to determine the maximum cooling and heating power required by the Heating Ventilation and Air Conditioning (HVAC) system. The computation ensures conditions of thermal comfort, considering the outdoor main temperature of Napoli (Fig.1).

Outdoor temperatures were uploaded from a database of location from around the world based on

\footnotetext{
* Corresponding author: gabriella.marone@unina.it
} 
ASHRAE 2013 design weather data implemented in the software [13]. A dynamic energy simulation devoted to determining thermal loads, has been performed by means of Design Builder. This software includes Energy-Plus tool able to model building cooling, heating, lighting, ventilation, and other energy flow [14]. In particular, the inlet water temperature in the primary circuit of energy pile induced by the heat pump has been determined for a plant operating over a period of one year.

To this aim several input parameters in Design Builder were set:

- Transmittance values of the main objects constituting the building envelope (walls, slabs, windows) were determined as average values according to Italian Laws and guidelines (D.M. 26/06/2015) on building energy performance.

- A hypothetical operation of the air conditioning system during one year with the resolution of the daily cycles was assumed. The GSHP plant works in a daily "on/off" mode from 8:00 a.m. to 18:00 p.m., from Monday to Friday. Furthermore, the plant does not work in April, May and October. In particular five operational conditions have been determined: 1) first cooling cycle of 90 days, 2) first recovery phase of 61 days, 3) heating cycle of 122 days, 4) second recovery cycle of 31 days, 5) second cooling cycle of 61 days (Fig.1).

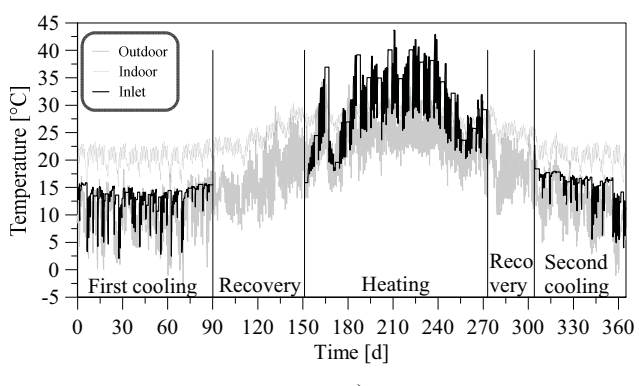

a)

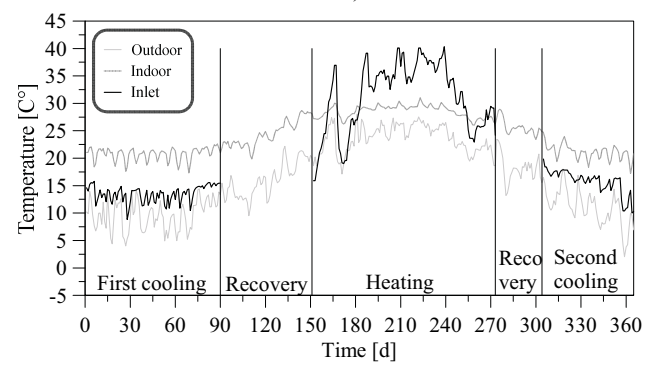

Fig. 1. (a) Hourly and (b) daily values of temperature of the water entering (inlet) the underground collector; outdoor and indoor temperatures.

The activities in the building have been set to "Generic Office Area" with a density of occupation of 0,111 person $/ \mathrm{m}^{2}$. Target temperatures of the internal air of the building have been assumed equal to $20^{\circ} \mathrm{C}(293 \mathrm{~K})$ for heating in the wintertime and $26^{\circ} \mathrm{C}(299 \mathrm{~K})$ for cooling in the summertime according to the provisions of UNI / TS 113000 (Fig.1).

As output of simulation, the hourly and daily inlet temperatures of the fluid entering the underground collector (heat exchanger system) and the hourly indoor mean air temperature have been obtained (Fig. 1). The inlet temperatures have been used as the thermal loadings along the energy pile discussed in Section 3. The difference between the inlet and outlet temperatures of the fluid in the pipes has not been considered as it is negligible.

\section{Thermo-mechanical modelling of a single EP in pyroclastic soil}

The thermo-mechanical behaviour of a virtual energy pile installed in multi-layered pyroclastic soil was simulated through the FEM code PLAXIS 2D. Thermomechanical coupled analyses in axisymmetric conditions have been performed adopting triangular fine mesh of 15 nodes (Fig. 2). A typical pyroclastic soil deposit of Campania region was considered. The geotechnical model used in the numerical simulations consists of three different layers of pyroclastic sands until $10 \mathrm{~m}$ of depth and a layer of grey tuff from $10 \mathrm{~m}$ to $30 \mathrm{~m}$ (Fig. 2). Site investigations and a conventional design pile load test, carried out within the framework of the design of the foundation system of a trade centre located in Napoli, were used to calibrate the mechanical parameters. A trial-and-error procedure, based on the experimental data reported by [15], was applied. Further details about the load tests and the site investigations are reported by $[15,16]$, while the load tests back analysis is described in [9]. A CFA pile, $13 \mathrm{~m}$ length with $0.60 \mathrm{~m}$ diameter, embedded in the tuff layer with a socket depth of $3 \mathrm{~m}$, was modelled. The geometry and the mesh adopted are reported in Fig. 2.

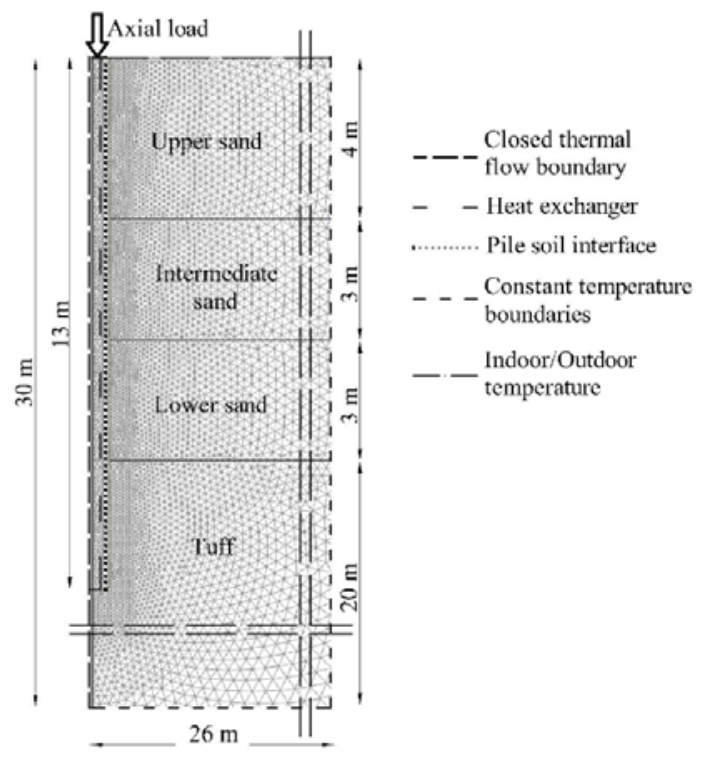

Fig. 2. Geometry, mesh and thermal boundaries conditions of the FE model. 
Table 1. Mechanical and thermal properties of the CFA pile and soil layers.

\begin{tabular}{|c|c|c|c|c|c|}
\hline & Pile & $\begin{array}{l}\text { Upper } \\
\text { sand }\end{array}$ & $\begin{array}{l}\text { Interme- } \\
\text { diate } \\
\text { sand }\end{array}$ & $\begin{array}{l}\text { Lower } \\
\text { sand }\end{array}$ & Tuff \\
\hline $\begin{array}{l}\text { Unit weight } \\
\text { (y) }\left[\mathrm{kN} / \mathrm{m}^{3}\right]\end{array}$ & 24 & 19 & 18 & 19 & 17 \\
\hline $\begin{array}{c}\text { Young's } \\
\text { modulus } \\
\left(\mathrm{E}_{50}\right)[\mathrm{MPa}]\end{array}$ & 30000 & 31.85 & 9.10 & 53.30 & 5000 \\
\hline $\begin{array}{c}\text { Young's } \\
\text { modulus } \\
\left(\mathrm{E}_{\mathrm{ur}}\right)[\mathrm{MPa}]\end{array}$ & - & 95.55 & 27.30 & 159.90 & - \\
\hline $\begin{array}{c}\text { Thermal } \\
\text { expansion } \\
\text { coefficient } \\
\left(\mathrm{a}_{\mathrm{s}}\right) \\
{\left[10^{-5} \mathrm{~K}^{-1}\right]}\end{array}$ & 1.2 & 4 & 4 & 4 & 4 \\
\hline $\begin{array}{l}\text { Thermal } \\
\text { conductivity } \\
\left(\lambda_{\text {eff }}\right)\left[\mathrm{W} \mathrm{m}^{-}\right. \\
\left.{ }^{1} \mathrm{~K}^{-1}\right]\end{array}$ & 2.4 & 2.4 & 2.4 & 2.4 & 1.4 \\
\hline $\begin{array}{c}\text { Specific } \\
\text { heat } \\
\text { capacity } \\
\text { (cs) }\left[\mathrm{J} \mathrm{kg}^{-1}\right. \\
\left.\mathrm{K}^{-1}\right]\end{array}$ & 100 & 1000 & 1000 & 1000 & 1300 \\
\hline $\begin{array}{l}\text { Cohesion } \\
\text { (c') }[\mathrm{kPa}]\end{array}$ & - & 1 & - & - & \\
\hline $\begin{array}{c}\text { Friction } \\
\text { angle }\left(\varphi^{\prime}\right) \\
{\left[{ }^{\circ}\right]}\end{array}$ & - & 37 & 32 & 37 & 28 \\
\hline $\begin{array}{c}\text { Dilatancy } \\
\text { angle }(\psi) \\
{\left[{ }^{\circ}\right]}\end{array}$ & - & 7 & 2 & 7 & - \\
\hline
\end{tabular}

Long-term predictions of energy piles' performance imply cyclic thermal loadings and consequently pile-soil interaction under cyclic quasi-static conditions should be considered. For instance, the thermally induced cyclic movements may cause cumulative degradation of the side friction leading to the alteration of shaft resistance. The pile expansion and contraction during the heating and cooling cycle may increase or decrease the contact pressure at pile- soil interface leading to changes in the mobilized frictional resistance. [17] found an increase of around $40 \%$ of the bearing capacity of a concrete energy pile installed in compacted silt under temperature difference of $41^{\circ} \mathrm{C}$, probably due to an increase of lateral soil pressure. [18] performed cavity expansion analyses and found that the change in radial stress is negligible for the range of possible thermal expansion strains therefore temperature-induced radial expansion of the pile would not increase pile capacity significantly. [19] explored the axial and radial thermal response of a bored pile equipped with three $U$ shaped heat exchangers. Measured radial thermal strains are close to pile free expansion or contraction, indicating minimal resistance from the surrounding soil i.e. developing of low radial thermal stresses. [20] investigate the axial and radial thermal responses of a field scale energy pile under building loads. Along pile shaft, axial thermal strains were more constrained than the radial thermal strains.
Both $[19,20]$ found that the radial strains are relatively small confirming that radial thermal expansion of the pile is not expected to contribute to the development of thermal stresses. Several experimental studies on finer soils, as Boom clay [21] and soft Bangkok clay [22], subjected to drained cyclic thermal load confirm that the material shows thermo-elastic response in $\mathrm{OC}$ conditions and both thermo-elastic and thermo-plastic response when subjected to NC conditions [23]. [24] found that floating piles in OC clays undergo a progressive thermally induced settlement at a reduced rate with increasing number of heat cycles. About behaviour of sand under drained cyclic thermal load, there are few studies $[25,26,28]$. [25] found that the first thermal cycle on Bangkok sand induced the largest strain increase while subsequent cycles gave rise to a progressively lower strain increase. [28] from model tests on energy piles in dry sand reported that the ultimate bearing capacity of the pile increased only about $5 \%$ during pile heating. [29] from centrifuge tests in saturated sand showed that the ultimate bearing capacity of an energy pile increased by $13 \%$ and $30 \%$ with temperature increases of $15{ }^{\circ} \mathrm{C}$ and $30{ }^{\circ} \mathrm{C}$ respectively. [30] investigated this aspect numerically for piles installed in sand, by assuming a cyclic interface constitutive law (degradation).

Despite the insights obtained from these studies, there is still a lack of understanding of thermal response of soil, especially sand, subjected to numerous thermal cycles which could contribute to further pile plastic displacements accumulation in long term condition and to changes in the mobilized frictional resistance. Herein, given the relatively small but realistic temperature range, these features are ignored, and relatively simple constitutive models are adopted. Different operational conditions have been analysed: annual thermal cycle with hourly or daily temperature variations. Two extreme thermal soil surface conditions are considered: the outdoor environmental temperature and indoor temperature of the building. The top three layers of pyroclastic sandy soil have been modelled by adopting the Hardening-Soil constitutive model while the bottom soil layer of tuff by Mohr-Coulomb constitutive model. The mechanical properties of the different soil layers are reported in table 1 .

\subsection{Thermo-mechanical behaviour of energy pile under hourly and daily thermal loads}

One year of operational condition is simulated through fully coupled transient thermo-mechanical calculations.

Two different cases, corresponding to different kinds of thermal loadings, are reported: cycles with Hourly Thermal Variations (HTV, Fig. 1a) and cycles with Daily Thermal Variations (DTV, Fig. 1b). For both cases the live mechanical load, equal to $40 \%$ of the ultimate bearing capacity of the pile-soil system $(2400 \mathrm{kN})$, is applied to the head of the pile and kept constant during the yearly thermal cycle. The groundwater temperature in Napoli varies between $16{ }^{\circ} \mathrm{C}$ and $18{ }^{\circ} \mathrm{C}[31,32]$, therefore the initial soil temperature was assumed equal 
to $17{ }^{\circ} \mathrm{C}$. Transient thermo-mechanical analyses have been carried out assigning thermal boundary conditions to the model (Fig. 2). At the bottom and the right side of the domain a constant temperature of $17^{\circ} \mathrm{C}$ was assigned. Soil temperature variation with depth has been neglected along the right-side frontier and a simplified condition has been assumed.

The vertical soil boundary at the right side of the model has been placed at forty-three times the pile diameter from the pile-soil interface, it is far enough from the pile and does not affect pile response. At soil surface the outdoor main temperature of air in Naples was assigned (Fig. 1a and Fig. 1b). Thermal loadings were imposed as a temperature-time variable functions (HTV or DTV, Fig. 1a and 1b) on a straight line inside the pile body corresponding to the potential location of the heat exchanger pipes. A coil-type primary circuit is considered and simulated via a cylindric constant temperature surface (in the axisymmetric model as a simple straight line) [8,9]. During one year of the operation, two recovery phases are modelled: the first of 61 days and the second of 31 days. Recovery phases were simulated not applying any thermal conditions to the pile.

The effects of the two different types of thermal load variations, DTV and HTV, are compared in terms of pile head displacements and axial load along the pile shaft in Fig 3 and 4, respectively. From Fig. 3 it is possible to notice that the trend of the pile head displacement follows the pile expansion and contraction induced by the thermal variations. The maximum incremental displacement observed for DTV is $4.40 \mathrm{~mm}$ and 4.86 $\mathrm{mm}$ for HTV. Comparing the displacement induced by the thermo-mechanical coupling to the displacement induced by mechanical loading $(3.21 \mathrm{~mm})$, DTV and HTV determine an additional displacement equal to 37 $\%$ and $51 \%$ of the mechanical displacement, respectively.

However, the absolute value of the difference between the maximum thermo-mechanical displacement induced by HTV and DTV is less than $0.5 \mathrm{~mm}$ and therefore it could be considered almost negligible for engineering applications.

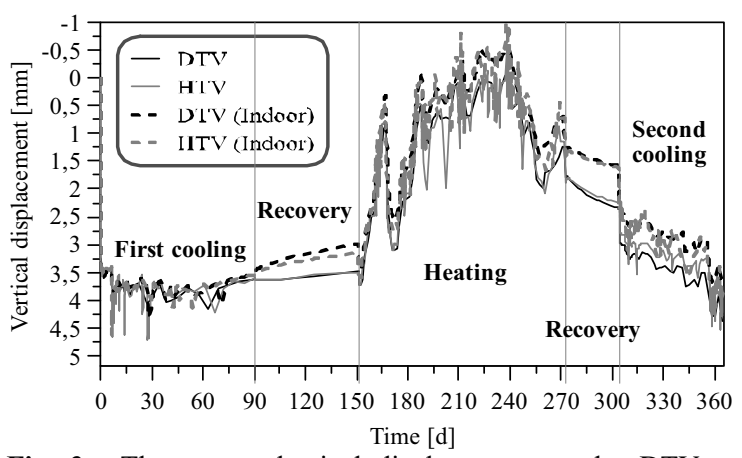

Fig. 3. Thermo mechanical displacements under DTV and HTV and different soil surface thermal conditions (Indoor and outdoor temperature).

Different time instants of the yearly thermal cycles, both in case of HTV or DTV, are chosen to illustrate the distribution of the axial load within the pile during heating, cooling and recovery phases (Fig. 4). The axial load along the pile induced by DTV and HTV combined to mechanical loading are compared with the case where only the live load is applied to the head of the pile (Mechanical case). For both kinds of thermal variations, DTV and HTV, heating the pile increases the axial loading along the shaft, and this effect, as expected, is more pronounced under hourly variations (Fig. 4). In the case of cooling the axial load for both DTV and HTV decreases with respect to the mechanical case (Fig. 4).

The axial load is reported also at the end of the second recovery phase (Fig. 4) where no thermal loadings are applied directly to the pile. During this phase, the axial load does not correspond to the purely mechanical case because there is still a thermal variation induced by the previous loading. At the end of the yearly operational condition, for both DTV and HTV the axial loading is smaller than the mechanical case. This effect could be attributed to the cooling at the end of thermal cycle i.e. the temperature of the pile is not back to the initial value. In terms of axial loading, DTV and HTV determine different axial load variations but the amount of these variations could be considered as negligible.

From the observed response, applying DTV or HTV does not determine substantial differences. On the other hand carrying out $\mathrm{FE}$ analyses with hourly thermal variations significantly increases the calculation efforts and does not lead to noticeable difference. The difference between the time resolution should be further investigated. With reference to the long term behaviour (i.e. 50 years) however the difference between DTV and HTV should be further investigated.
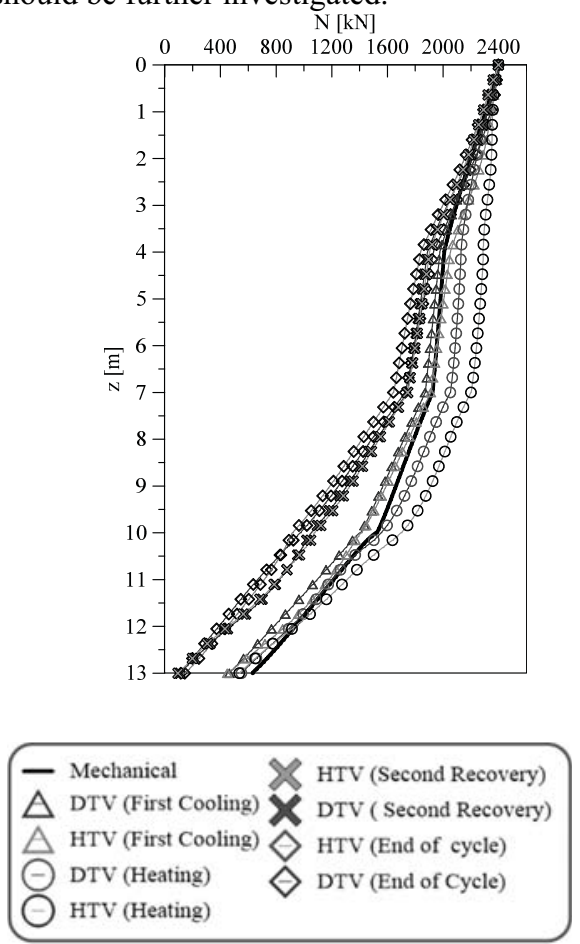

Fig. 4. Axial load along the pile shaft for thermo-mechanical case (HTV or DTV) and purely mechanical case. 


\subsection{Effects of the surface boundary conditions}

Another aspect that needs to be further investigated is the coupling of the effects of the imposed surface boundary condition and the pile thermal loadings. If the foundations of a building are thermally activated the thermo-mechanical response observed in the pile could be affected by the superposition of the heat flow from the structure and the thermal loading within the pile [33].

In this study, for the surface boundary conditions two extreme cases were defined: (i) the surface temperature corresponds to the outdoor temperature (the results discussed above), (ii) the surface temperature corresponds to the building indoor temperature. For these thermal surface boundary conditions, DTV analyses were performed. In the already mentioned Fig. 3 , the thermal surface effects are compared in terms of pile head displacements. The influence of the different boundary conditions is explored in terms of axial load along the pile shaft in Fig. 5. The maximum pile head settlement considering Indoor temperature variations at soil surface is $4.31 \mathrm{~mm}$. This value is very close to the maximum value found by applying outdoor surface temperature conditions showing the very limited influence of the two different boundary conditions on the computed displacements. On the other hand, in Fig. 5 the axial load along the shaft is reported for different phases of the thermal cycle (first cooling, heating and recovery phases). During the two recovery phases, the assigned surface boundary condition has a more pronounced effect on the axial loading distribution.
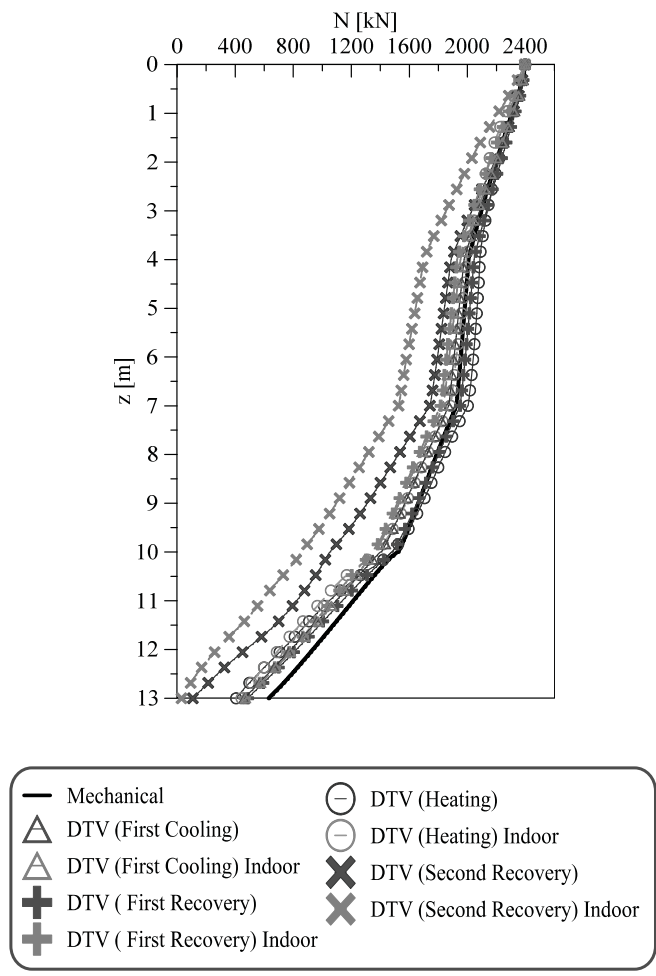

Fig. 5. Axial load along the pile shaft for thermo-mechanical cases and DTV considering different soil surface thermal conditions (Indoor and Outdoor temperature).
Comparing the axial load along the shaft, during the different phases, it could be noticed that the difference between the two simulated surface conditions is of about 10 to $15 \%$ on the average. In the case of heating, applying the indoor thermal variations to the top of the domain determines a lower axial load compared to the outdoor thermal case. During cooling modes the difference between the two surface cases is smaller, the indoor temperature assumption determines a smaller axial load compared to the outdoor temperature assumption. During both first cooling and heating cycles, as shown by the results plotted in Fig. 5, the effect of the surface boundary condition is mitigated. The largest difference between the two thermal conditions occurs during the two recovery phases, when the system does not work the surface boundary condition is the only thermal loading applied to the system. This is evident in Fig. 6 a) and b) where the field temperature during the second recovery phase is reported. When indoor temperature is considered at the boundary the temperature values computed down in the subsoil are higher than the corresponding values under outdoor conditions. On the other hand, Fig. $6 \mathrm{c}$ and d clearly show the smaller influence of the thermal boundary conditions during the heating phase which is presumably governed by the DTV applied within the pile. As concluding remark, from the results both in terms of axial loading and pile head displacement, the outdoor temperature variation assumed as surface boundary condition seems to be the most conservative design assumption.

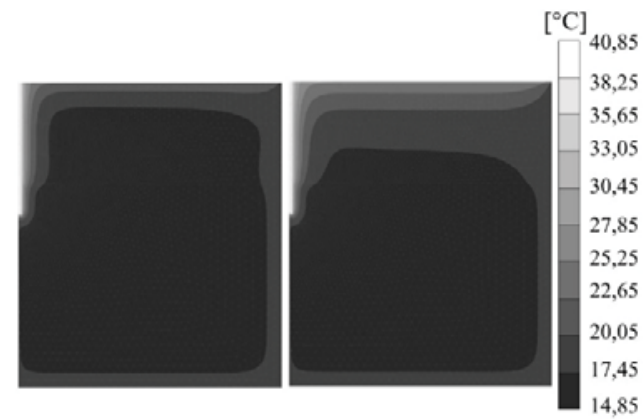

a)

b)

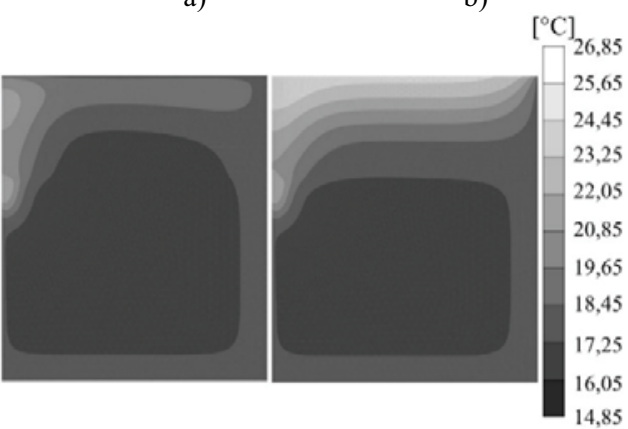

c)

d)

Fig.6. Temperature fields: second recovery phase corresponding to (a) outdoor temperature and (b) indoor temperature applied at the surface; heating phase corresponding to c) outdoor temperature and d) indoor temperature applied at soil surface. 


\section{Conclusions}

The thermo-mechanical response of an isolated endbearing pile under thermal loads with different time resolutions and different thermal surface boundary conditions has been presented. Thermal loadings applied to the pile were computed by means of Design Builders software allowing to perform realistic simulations. The effect on pile-soil interaction was evaluated in terms of pile head displacements and axial load along the pile shaft. The pile's mechanical response under thermal variations with different time trends, DTV and HTV, were first compared. HTV induced pile heads' displacements (upwards and downwards) greater than those induced by DTV while the axial load distribution along the pile shaft is very similar in both cases. Of course, the high computational effort connected to the numerical simulations using HTV, and the small difference on the induced effects by DTV and HTV lead to conclude that DTV is the most convenient assumption.

However, it is possible that differences between DTV or HTV may not always be considered negligible, both from a geotechnical and structural point of view. The effects of the different thermal surface boundary condition on the pile-soil thermo-mechanical interaction were also investigated. Two limit conditions were considered at soil surface: the outdoor air temperature and the building indoor temperature. The latter assumption provides a simplified and quick method to indirectly involve the superstructure heat flows in the problem. In the modelled recovery phases, the differences between the two assumptions are more pronounced, especially looking at the pile head displacements versus time graph (Fig. 3). In regions where the recovery phase may be lasting longer than the ones in the Napoli area this effect may be even more important and pronounced. During these phases, however, the only thermal loading indirectly acting on the pile is the thermal surface one. Instead, during the heating and cooling cycles, the difference between the two upper boundary conditions are rather small: the outdoor temperature leading to greater pile head displacements and axial load variations.

\section{References}

1. A. Di Donna, L. Laloui. Numerical analysis of the geotechnical behaviour of energy piles. Int. J. Numer. Anal. Meth. Geomech., 39 (8), 28 (2015).

2. P. Bourne-Webb, B. Amatya, K. Soga, T. Amis, C. Davidson, P. Payne. Energy pile test at Lambeth College, London: geotechnical and thermodynamic aspects of pile response to heat cycles. Geotechnique, 59(3), 11 (2009).

3. L. Laloui, M. Nuth, L. Vulliet. Experimental and numerical investigations of the behaviour of a heat exchanger pile. International journal for numerical and analytical methods in geomechanics, 30(8), 18 (2006).
4. KD. Murphy, JS. McCartney. Seasonal response of energy foundations during building operation Geotec.Geol. Eng. 33(2), 13 (2015).

5. PJ. Bourne Webb, TM. Bodas Freitas, R.M. Freitas Assuncao. Soil-pile thermal interactions in energy foundations. Geotechnique, 66(2), 4 (2016).

6. TM. Bodas Freitas, F. Cruz Silva, PJ. Bourne-Webb. The response of energy foundations under thermomechanical loading .19th International Conference on Soil Mechanics and Geotechnical Engineering, Paris, 4 (2013).

7. G. Russo, MRS. Maiorano, G. Marone. Analysis of thermo-mechanical behaviour of energy piles. Geotec. Eng. Journal of the SEAGS \& AGSSEA Journal, 50 (3), 7 (2019).

8. G. Marone, L. Di Girolamo, G. Russo. Studio parametrico del comportamento di un palo singolo sottoposto a carichi termo-meccanici IAGIG 2019, 4, (2019).

9. RMS. Maiorano, G. Marone, G. Russo, L. Di Girolamo. Experimental behaviour and numerical analysis of energy piles. XVII ECSMGE, 8 (2019).

10. CL. Wang., H. Liu, G. Kong, CWW. Ng. Different types of energy piles with heating-cooling cycles. Proceedings of the Institution of Civil EngineersGeotechnical Engineering, 170, 11 (2017).

11. N. Yavari, AM. Tang, JM. Pereira, G Hassen. Experimental study on the mechanical behaviour of a heat exchanger pile using physical modelling. Acta Geotechnica, 9(3), 13 (2014).

12. CA. Kramer, P. Basu. Performance of a model geothermal pile in sand. 8th International conference on physical modelling in geotechnics, Perth., 7 (2014).

13. Design Builder Location Templates: https://designbuilder.co.uk/helpv6.0/\#Location Tem plates.htm Design Builder Guide : https://designbuilder.co.uk/helpv6.0/\#GetStarted.ht $\mathrm{m} \% 3$ FTocPath\%3DGet\%2520Started\%7C $0 \mathrm{~J}$

14. G. Russo. Experimental investigations and analysis on different pile load testing procedures. Acta Geotechnica, 8 (1), 14 (2013).

15. G. Russo, G. Marone. Experimental comparison on different pile load testing methods. Experimental comparison on different pile load testing methods. DFI-EFFC Int. Conf. on Deep Found. and Ground Improvement: Urbanization and Infrastructure Development-Future Challenges, Rome, 11 (2018).

16. JS. McCartney, JE. Rosenberg. Impact of Heat Exchange on Side Shear in Thermo-Active Foundations Geo-frontiers 2011: Advances in Geotechincal engeneering, ASCE, 11 (2011).

17. CG. Olgun, TY. Ozudogru, and CF. Arson. Thermo-mechanical radial expansion of heat exchanger piles and possible effects on contact pressures at pile-soil interface. Geolett, 4(3),9 (2014). 
18. M. Faizal, A.Bouazza, C.Haberfield, JS. McCartney. Axial and Radial Thermal Responses of a FieldScale Energy Pile under Monotonic and Cyclic Temperature Changes. Journal of Geotec. and Geoenv. Eng. 144(10), 14 (2018).

19. M. Faizal, A. Bouazza, JS. McCartney, C. Haberfield. Axial and radial thermal responses of energy pile under six storey residential building. Canadian Geotec. Journal, 56(7), 15 (2019).

20. N. Sultan, P. Delage, YJ. Cui. Temperature effects on the volume change behaviour of Boom clay. Eng Geol., 64, 11 (2002).

21. HM. Abuel-Naga, DT. Bergado, A. Bouazza, G. Ramana. Volume change behaviour of saturated clays under drained heating conditions: experimental results and constitutive modelling. Can Geotech J., 44, 14 (2007).

22. A. Di Donna, L. Laloui. Response of soil subjected to thermal cyclic loading: Experimental and constitutive study Eng Geol., 190, 12 (2015).

23. CWW. Ng, C. Shi, A. Gunawan, L. Laloui. Centrifuge modelling of energy piles subjected to heating and cooling cycles in clay. Geotech letters, 4 (4), 6 (2014) .

24. J. Sittidumrong, A. Jotisankasa, K. Chantawarangul. Effect of thermal cycles on volumetric behaviour of Bangkok sand. Geomechanics for Energy and the Environment, 20, 12 (2019).

25. CWW. Ng, S.H. Wang, C. Zhou. Volume change behaviour of saturated sand under thermal cycles. Géotech Lett., 6(2), 8 (2016).

26. H. Liu, H. Liu, Y. Xiao, JS. McCartney. Influence of Temperature on the Volume Change Behavior of Saturated Sand. ASTM Geotech Test J. 2018, 41(4), 11 (2018).

27. J. Goode III, JS. McCartney. Centrifuge Modeling of End-Restraint Effects in Energy Foundations. Journal of Geotech Geoenviron Eng, 141 (8), 13 (2015).

28. HL. Liu, CL. Wang, GQ. Kong, A. Bouazza. A simplified design method for energy piles. Acta Geotechnica, 14, 10 (2019).

29. ME. Suryatriyastuti, H. Mroueh, S. Burlon. Numerical Analysis of the Bearing Capacity of Thermoactive Piles Under Cyclic Axial Loading. Energy Geostructures: Innovation in Underground Engineering, 17 (2013).

30. G. Colombo. Il congelamento artificiale del terreno negli scavi della metropolitana di Napoli: valutazioni teoriche e risultati sperimentali RIG, XLIV (4), 21 (2010).

31. D. Ludovico. Modello idrogeologico del sito di interesse nazionale - sin - "Napoli orientale" Thésis, 52 (2007).

32. PJ. Bourne Webb, TM. Bodas Freitas, RM. Freitas Assuncao. A review of pile-soil interactions in isolated, thermally-activated piles. Computers and Geotechnics, 108, 13 (2019). 